\title{
Congenital hypopituitarism due to congenital craniopharyngioma: First case in Sri Lanka
}

\author{
*Jananie Suntharesan ${ }^{1}$, Buddhi Gunasekara ${ }^{1}$, Navoda Atapattu ${ }^{1}$ \\ Sri Lanka Journal of Child Health, 2021; 50(1): 162-164 \\ DOI: http://dx.doi.org/10.4038/sljch.v50i1.9421 \\ (Key words: Craniopharyngioma, congenital hypopituitarism, micropenis)
}

\section{Introduction}

Congenital intracranial tumours are very rare and only account for $0.5-1.9 \%$ of all the congenital tumours ${ }^{1}$. Teratoma is the most common and craniopharyngioma accounts for $11 \%$ of all congenital intracranial tumours ${ }^{1}$. It can be diagnosed antenatally by ultrasound scan (USS) followed by magnetic resonance imaging (MRI) ${ }^{1}$. They commonly present with intracranial mass, macrocephaly, hydrocephalus and still birth ${ }^{1}$. Only a few cases of congenital craniopharyngioma have been reported to date ${ }^{2}$. Congenital hypopituitarism can present as an isolated entity or as combined pituitary hormone deficiency, commonly due to mutations in genes involved in pituitary development ${ }^{3}$. Craniopharyngioma is a very rare cause of congenital hypopituitarism. We report the first case of congenital craniopharyngioma in Sri Lanka presenting with congenital hypopituitarism.

\section{Case report}

A 4 month old male infant was referred from the local hospital due to micropenis ${ }^{3,4}$. He was born to non-consanguineous parents as the first child. The antenatal period was neither complicated with gestational diabetes nor pregnancy induced hypertension. Antenatal USS done at 28 weeks at the local hospital was unremarkable. Emergency caesarean section was done due to placenta praevia at 38 weeks of gestation. His birth weight was $2900 \mathrm{~g}$. He had icterus needing phototherapy during the postnatal period. He had adequate weight gain, without a history of polyuria or hypoglycaemia. His development was age appropriate.

Examination revealed an open anterior fontanelle with an occipito-frontal circumference of $41.5 \mathrm{~cm}$, which was on the fiftieth percentile. Weight and height were $7.05 \mathrm{~kg}$ and $61 \mathrm{~cm}$ respectively, which were on -1 SD in the growth chart. He did not have mid-facial hypoplasia, cleft palate, bifid uvula or limb abnormality such as polydactyly. Cardiovascular and respiratory system examinations were unremarkable. $\mathrm{He}$ had micropenis. Stretch penile length was $2 \mathrm{~cm}$ with hypoplastic scrotal sac and $1 \mathrm{~cm}$ atrophic small testes bilaterally. His eye examination was normal. Biochemical investigations revealed multiple pituitary hormone deficiencies (Table 1).

Table 1: Investigation summary

\begin{tabular}{|l|c|c|}
\hline \multicolumn{1}{|c|}{ Investigation } & Initial Evaluation & Follow up \\
\hline Luteinizing hormone & $<0.07 \mathrm{IU} / 1$ & \\
\hline Follicle stimulating hormone & $0.07 \mathrm{IU} / \mathrm{L}$ & \\
\hline Basal cortisol & $<22 \mathrm{nmol} / 1$ & \\
\hline Short Synacthen Test: $0 \mathrm{~min}$ & $<22 \mathrm{nmol} / 1$ & \\
\hline Free thyroxine (9-25pmol/1) & $78.7 \mathrm{nmol} / 1$ & $7.2 \mathrm{pmol} / 1$ \\
\hline Thyroid stimulating hormone (1.82-8.21 IU/l) & $10.1 \mathrm{pmol} / 1$ & $1.98 \mathrm{IU} / 1$ \\
\hline
\end{tabular}

${ }^{1}$ Lady Ridgeway Hospital for Children, Colombo, Sri Lanka

*Correspondence: jananiesuntharesan@gmail.com

https://orcid.org/0000-0001-7158-999X

(Received on 22 April 2020: Accepted after revision on 22 May 2020)

The authors declare that there are no conflicts of interest

Personal funding was used for the project.

Open Access Article published under the Creative

Commons Attribution CC-BY (c) (i) License
Both his luteinizing hormone and follicular stimulating hormone levels were low. He had a decreased basal cortisol level with poor response to the short synacthen test. His thyroid function tests were normal. He was commenced on oral hydrocortisone replacement therapy $10 \mathrm{mg} / \mathrm{m}^{2} /$ day. Three monthly follow up was arranged to monitor thyroid function, growth and development. As the common cause for hypopituitarism is development abnormality in the pituitary gland due to genetic mutations in the gene for pituitary development, routine MRI of the brain was planned at the age of 1 year. At this point USS of the brain was not 
performed. He was started on complementary feeding at the age of six months and continued frequent breast feeding without formula feeds. During follow up child had excessive weight gain which was crossing the centiles. At 11 months of age child presented to the local hospital with vomiting and bulging fontanelle suggestive of raised intracranial pressure. USS of the brain and contrast enhanced computed tomography (CECT), followed by MRI of the brain, done at that point showed a solid lesion with cystic component involving sellar and suprasellar region measuring $4.3 \mathrm{~cm} \times 2.8 \mathrm{~cm} \times 4.3 \mathrm{~cm}$, compressing the $3^{\text {rd }}$ ventricle and leading to obstructive hydrocephalus. Pituitary gland and optic chiasma were not seen separately (Figure 1).

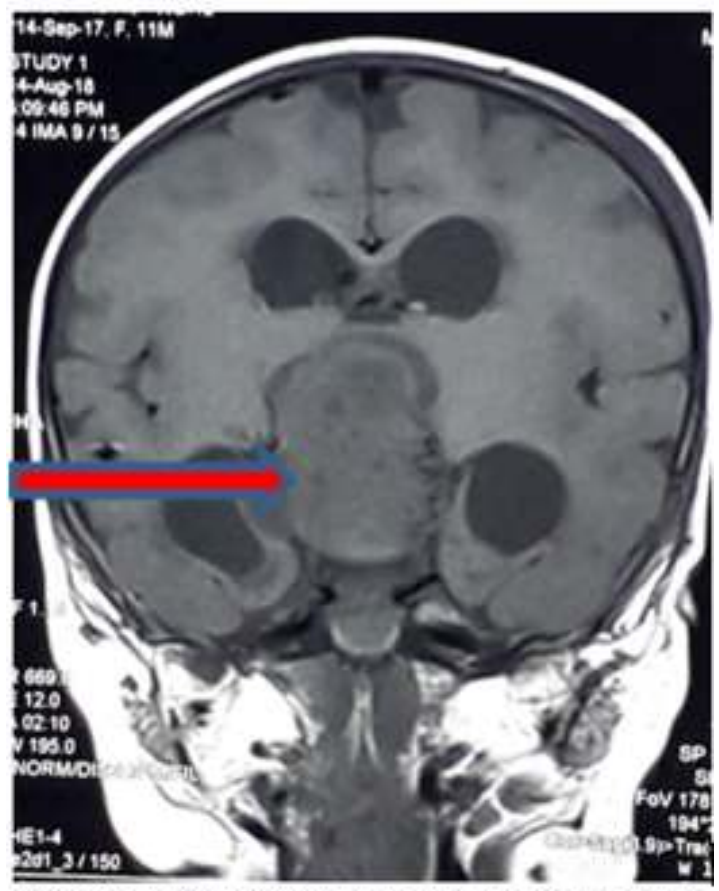

Figure 1: MRI of brain showing solid lesion with cystic component involving sellar and suprasellar region measuring $4.3 \mathrm{~cm} \times 2.8 \mathrm{~cm} \times 4.3 \mathrm{~cm}$

Ventricular peritoneal shunt was inserted, followed by excision of craniopharyngioma at the age of 1 year and 1 month. Following surgery child needed multiple pituitary hormones including desmopressin, thyroxine and hydrocortisone replacement. Postoperatively, child had lost developmental milestones in all four domains which he achieved preoperatively. It was associated with complete loss of vision in both eyes and he also needed tracheostomy. Neurosurgery, endocrinology, ear nose and throat (ENT) and paediatric clinic follow up were arranged.

\section{Discussion}

Craniopharyngioma is categorised as a tumour of the sellar region ${ }^{4}$. Although the World Health Organisation (WHO) classified it as a grade one tumour ${ }^{5}$, its location and pressure effects lead to pituitary hypofunction and visual disturbance. There are 2 types of craniopharyngioma, adamantinomatous and papillary. Adamantinomatous type is commoner in children ${ }^{6}$. Rathke's pouch is an out pouching of ectodermal roof during embryogenesis. It extends cranially to form the anterior pituitary gland. Craniopharyngeal duct, which is the extension during cranial migration, later involutes. Remnants of embryonic cells proliferate around the extension and can develop into a craniopharyngioma ${ }^{5}$. Even though craniopharyngioma is a childhood tumour, embryonic cell proliferation can occur even in the antenatal period ${ }^{6}$.

Craniopharyngioma causes deficiency of multiple pituitary hormones including growth hormone (GH), thyroid stimulating hormone (TSH), adrenocorticotropic hormone (ACTH), follicle stimulating hormone (FSH), luteinizing hormone $(\mathrm{LH})$, and arginine vasopressin (AVP). The clinical presentation of hypopituitarism is variable in the neonatal period and manifests over time. Hypoglycaemia, lethargy, poor weight gain, hyponatraemia without hyperkalaemia, recurrent sepsis, haemodynamic instability, neonatal cholestasis and prolonged jaundice, polyuria and micropenis in male are observed in the neonatal period. Craniopharyngioma causes hypothalamic dysfunction which leads to obesity and metabolic dysfunctions ${ }^{7}$.

Total resection of the tumour is the treatment modality. Radiotherapy is contraindicated due to the small age ${ }^{2}$. Even with improving neurosurgical technology prognosis is poor due to the age of the child, size and location of the tumour ${ }^{2}$. This case highlights the very rare congenital cause of hypopituitarism. Antenatal and early postnatal imaging even with the USS of brain will help early diagnosis. Congenital craniopharyngioma leading to hypopituitarism needs coordinated care with multiple specialties.

\section{Acknowledgements}

We thank Dr. Jeyapalan Sivalingam, paediatrician district general hospital Vavuniya, Dr. Dilusha Prematilake and Dr. Raihana Hashim, Senior Registrar in Paediatric Endocrinology for their invaluable help.

\section{References}

1. Hirsig LE, Rajderkar DA. Fetal intracranial neoplasm-not always a teratoma! Journal of Radiology and Imaging 2016; 1(2):14-7. https://doi.org/10.14312/2399-8172.20164 
2. Isaacs $\mathrm{H}$ Jr. Perinatal brain tumors: a review of 250 cases. Pediatric Neurology 2002; 27(5):333-42. https://doi.org/10.1016/S08878994(02)00459-9

3. Kurtoğlu S, Özdemir A, Hatipoğlu N. Neonatal hypopituitarism: Approaches to diagnosis and treatment. Journal of Clinical Research in Pediatric Endocrinology 2019; 11(1):4-12.

https://doi.org/10.4274/jcrpe.galenos.2018 .2018 .0036

PMid: 29739730 PMCid: PMC6398195

4. Kollurage DUA, Atapattu N, Jayamanna BDW, Gunasiri WJR, de Silva KSH. Assessment of the stretched penile length in Sri Lankan newborns. Ceylon Medical Journal 2019; 64(1):4 -8.

https://doi.org/10.4038/cmj.v64i1.8823

PMid: 31055901

5. Louis DN, Perry A, Reifenberger G, von Deimling A, Figarella-Branger D, Cavenee WK, et al. The 2016 World Health Organization Classification of
Tumours of the Central Nervous System: a summary. Acta Neuropathologica 2016; 131(6):803-20.

https://doi.org/10.4038/cmj.v64i1.8823

PMid: 31055901

6. Prabhu VC, Brown HG. The pathogenesis of craniopharyngiomas. Child's Nervous System 2005; 21(8-9): 622-7. https://doi.org/10.1007/s00381-005-11909

PMid: 15965669

7. Roth C, Wilken B, Hanefeld F, Schröter W, Leonhardt U. Hyperphagia in children with craniopharyngioma is associated with hyperleptinaemia and a failure in the downregulation of appetite. European Journal of Endocrinology 1998; 138:8991. https://doi.org/10.1530/eje.0.1380089 PMid: 9461323 